\title{
String sign recovery of the left internal mammary artery bypass graft
}

Marc M. Yazbeck, MD, ${ }^{a}$ Victor A. Jebara, MD, ${ }^{b}$ and Rabih R. Azar, MD, MPH, FACC, ${ }^{a}$ Beirut, Lebanon

From the Divisions of ${ }^{\mathrm{a}}$ Cardiology and ${ }^{\mathrm{b} C a r d i o t h o r a c i c ~ S u r g e r y, ~ H o t e l ~ D i e u ~ d e ~ F r a n c e ~ H o s p i t a l ~ a n d ~ t h e ~ S t ~ J o s e p h ~}$ University Faculty of Medicine, Beirut, Lebanon.

Disclosures: The authors reported no conflicts of interest.

The Journal policy requires editors and reviewers to disclose conflicts of interest and to decline handling or reviewing manuscripts for which they may have a conflict of interest. The editors and reviewers of this article have no conflicts of interest.

Received for publication June 28, 2021; accepted for publication Nov 12, 2021; available ahead of print Nov 23, 2021.

Address for reprints: Rabih R. Azar, MD, MPH, FACC, Cardiology Department at Hotel Dieu de France Hospital, Bvld Alfred Naccache - Achrafieh, Beirut BP 166830, Lebanon (E-mail: razarmd@hotmail.com).

JTCVS Techniques 2022;12:72-4

2666-2507

Copyright $\odot 2021$ The Author(s). Published by Elsevier Inc. on behalf of The American Association for Thoracic Surgery. This is an open access article under the CC BY-NC-ND license (http://creativecommons.org/licenses/bync-nd/4.0/).

https://doi.org/10.1016/j.xjtc.2021.11.014

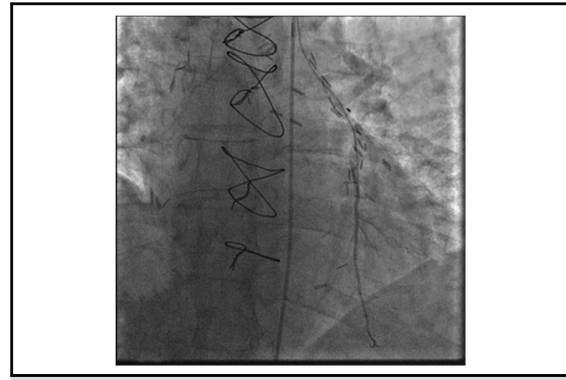

String sign of the left internal mammary artery.

\section{CENTRAL MESSAGE}

This is a demonstration of the "reversibility" of the LIMA string sign that had occurred when the stenosis on the native vessel had progressed and became hemodynamically significant.

See Commentaries on pages 75 and 77.

A 75-year-old patient was diagnosed with 3-vessel disease on coronary angiography in 2006 after an electrocardiogram (ECG)-positive treadmill exercise test. He underwent coronary artery bypass surgery: left internal mammary artery (LIMA) to left anterior descending (LAD) artery, saphenous vein graft to diagonal artery, saphenous vein graft to left marginal artery, and saphenous vein graft to right coronary artery.

In 2014, a coronary angiography was performed after an ECG-positive treadmill exercise test. It showed a nonobstructive mid-LAD stenosis and a string sign of the LIMA, with a dominant anterograde coronary flow through
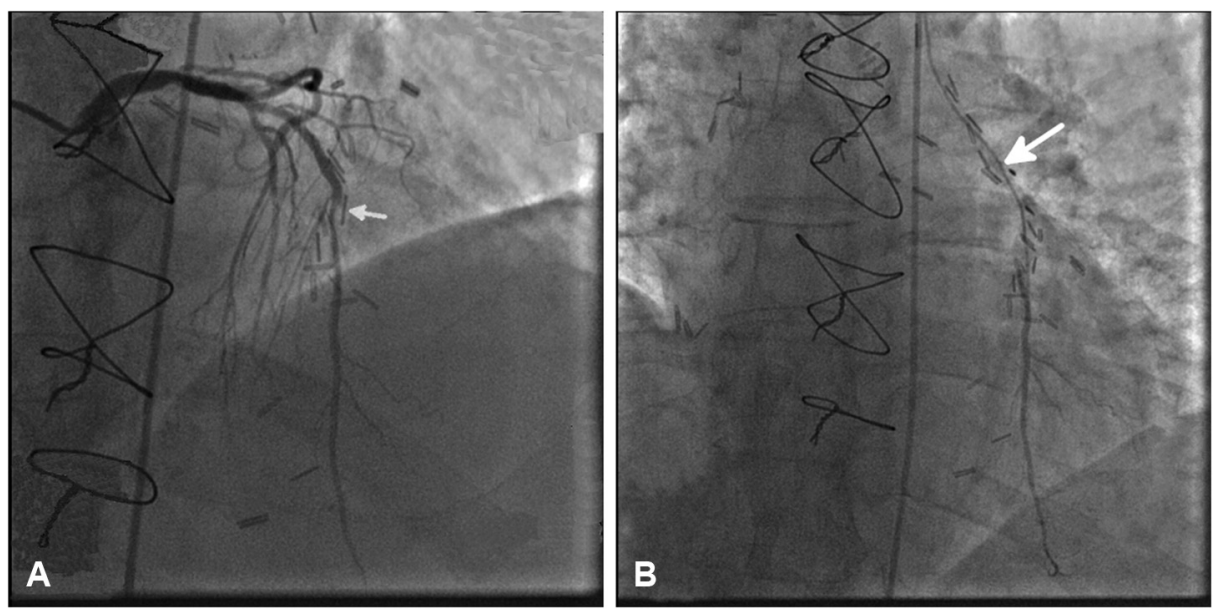

FIGURE 1. Coronary angiogram performed in 2014. A, Left anterior descending artery stenosis. Stenosis is angiographically nonsignificant (white arrow) with competitive flow filling the mid- and distal left anterior descending artery. B, String sign (white arrow) of the left internal mammary artery. 


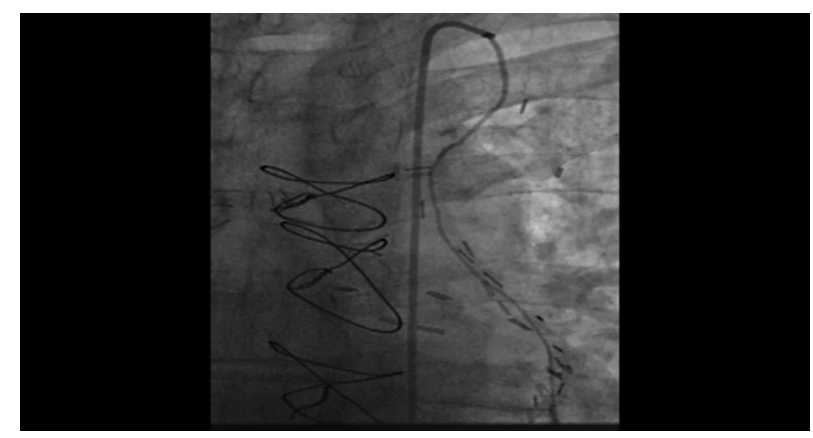

VIDEO 1. The string sign. Coronary angiogram performed in 2014 showing the string sign of the left internal mammary artery graft to the left anterior descending artery (Figure 1). Video available at: https:// www.jtcvs.org/article/S2666-2507(21)00771-9/fulltext.

the native LAD artery (Figure 1, Video 1). The 3 saphenous vein grafts were patent.

In January 2021, a coronary angiography was redone because of an ECG-positive treadmill exercise test. It

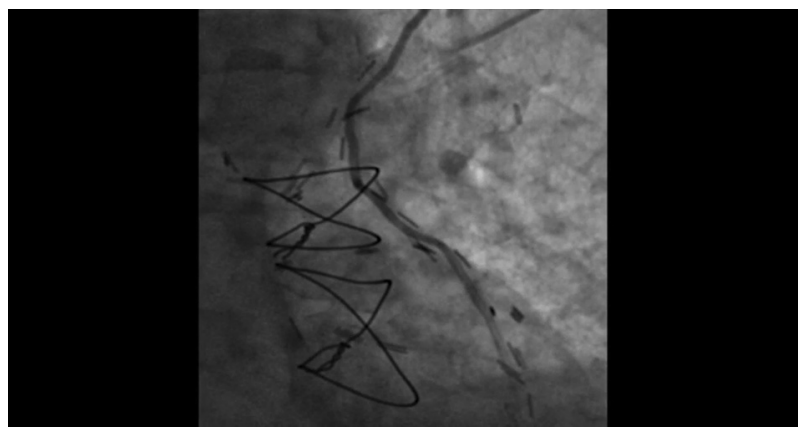

VIDEO 2. Reversal of the string sign. Coronary angiogram performed in 2021 showing the reversal of the string sign of the left internal mammary artery graft after development of a severe stenosis in the distal left main and proximal left anterior descending artery (Figure 2). Video available at: https://www.jtcvs.org/article/S2666-2507(21)00771-9/fulltext.

showed a new tight distal left main stenosis and a progression of the LAD stenosis. Contrary to 2014, the string sign of the LAD has now disappeared, and that vessel was well
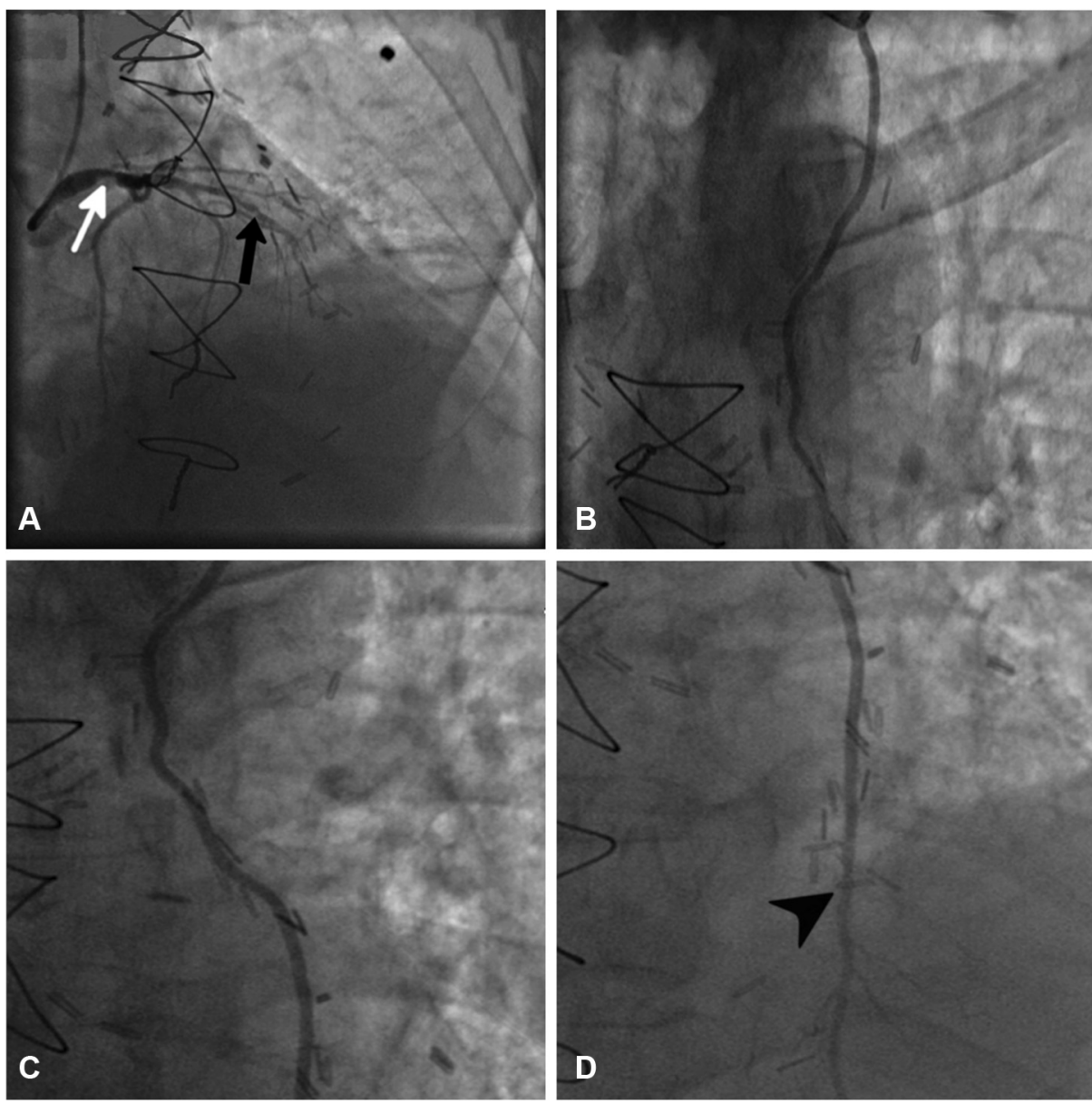

FIGURE 2. Coronary angiogram performed in 2021. A, Progression of native coronary artery disease, with tight stenosis in the distal left main (white arrow) and severe stenosis in the proximal left anterior descending artery (black arrow). B-D, Images from the same sequence showing complete reversibility of the string sign of the left internal mammary artery graft. Arrowhead indicates the left internal mammary artery anastomosis on the left anterior descending artery. 
developed and was the main pathway for perfusion of the mid- and distal LAD artery (Figure 2, Video 2).

It is well known that competitive flow can narrow internal mammary artery grafts (string sign). Hartman and colleagues ${ }^{1}$ suggested that LIMA string sign grafts are "living conduits" that can adapt to myocardial stress conditions when myocardial oxygen demand is increased. This is a demonstration of the "reversibility" of the LIMA string sign that had occurred when the stenosis on the native vessel had progressed and became hemodynamically significant. We obtained oral informed consent from the patient for publication of this case report. Institutional review board approval for this report was not required by our institution.

\section{Reference}

1. Hartman J, Kelder H, Ackerstaff R, van Swieten H, Vermeulen F, Bogers A. Preserved hyperaemic response in (distal) string sign left internal mammary artery grafts. Eur J Cardiothorac Surg. 2007;31:283-9. https://doi.org/10.1016/ j.ejcts.2006.11.016 